\section{Differential Acute Effects of Aldosterone, Dexamethasone, and Hyperkalemia on Distal Tubular Potassium Secretion in the Rat Kidney}

\author{
Michael J. Field, Bruce A. Stanton, \\ and Gerhard H. Giebisch \\ Department of Physiology, Yale University School of Medicine, \\ New Haven, Connecticut 06510
}

A

bstract. To determine the specific effects on renal potassium transport of acute elevations in plasma aldosterone, dexamethasone, and potassium concentrations, we studied adrenalectomized rats prepared such that each factor could be varied independently. Clearance data alone could not be used to deduce the underlying tubular transport effects, however, since infusion of each of these agents was associated with a marked change in urinary flow rate, which may itself have influenced potassium excretion. We therefore used a technique of continuous microperfusion, in vivo, of single superficial distal tubules to evaluate potassium secretion at constant luminal flow rate during each experimental maneuver. Acute aldosterone infusion was associated with a $90 \%$ stimulation of potassium secretion by microperfused tubules. However, total kidney sodium excretion and urinary flow rate were markedly reduced, and these factors opposed the direct tubular action of aldosterone, resulting in no net change in the amount of potassium excreted into the final urine. Conversely, dexamethasone had no direct effect on potassium secretion by single microperfused tubules, but it caused a sharp increase in urinary flow and sodium excretion, and secondarily enhanced urinary potassium excretion by $50 \%$. Hyperkalemia per se stimulated renal potassium excretion both via a direct tubular effect and by increasing urinary

Portions of this study have been published previously in abstract form (1984. Kidney Int. 25:300; and 1984. Abstracts IXth International Congress of Nephrology. 412A).

Address correspondence to Dr. Giebisch.

Received for publication 2 April 1984 and in revised form 12 July 1984.

J. Clin. Invest.

(c) The American Society for Clinical Investigation, Inc. 0021-9738/84/11/1792/11 \$1.00

Volume 74, November 1984, 1792-1802 flow rate. We conclude that urinary potassium excretion after infusion of each of these agents represents the net result of direct tubular effects and secondary flowmediated changes.

\section{Introduction}

It has long been considered that the classical renal effects of aldosterone, the prototypic mineralocorticoid hormone, are an increase in sodium reabsorption accompanied by an increase in potassium excretion (1). While the antinatriuretic action of aldosterone is universally recognized, there has been some reevaluation in recent years of the hormone's role in renal potassium metabolism. Although evidence from animal studies $(2,3)$, as well as from clinical experience $(4,5)$, generally supports a role for chronic alterations in plasma aldosterone levels in regulating potassium balance, there is less agreement regarding its acute effect on renal potassium handling. Thus, as pointed out in a recent review (6), relatively few published reports demonstrate a kaliuretic response to acute aldosterone administration, and these results are often obtained only under conditions of sodium loading or potassium depletion, which make the physiological meaning of the findings uncertain.

One important factor bearing on this controversy is the use by previous investigators of inappropriately high doses of aldosterone, or of excessive maintenance doses of glucocorticoids, leading to relatively nonspecific renal effects (7-10). A second difficulty in interpreting many published studies is the frequent occurrence, after acute hormone administration, of simultaneous changes in other factors, particularly urinary sodium concentration and flow rate, which are known to have a potent influence upon the potassium secretory mechanism of the distal nephron (11). For example, a fall in urinary sodium concentration and a slowing of urinary flow rate are commonly observed after aldosterone administration. Since both of these changes would in themselves inhibit renal potassium secretion, they may act to oppose and thus obscure any direct stimulatory effect of the hormone itself on tubular potassium transport. It is of interest in this regard that very 
few micropuncture studies of distal tubular potassium transport in adrenalectomized animals have been published (12-14), and in none of these has the specific effect of aldosterone on potassium secretory rates been examined. It was the prime purpose of the present study to address this issue directly.

A problem related to the one discussed above is the question of what role aldosterone plays in the renal response to an acute potassium load in the normal animal. In a recent report from this laboratory (15), we showed that the infusion of potassium chloride into intact rats results in an increase both in renal potassium excretion, and in potassium secretion by distal tubules perfused at a constant rate in vivo. It was not possible in that study to define the specific stimuli for these responses, however, since in animals with intact adrenals, potassium infusion provokes a sharp rise in aldosterone secretion as well as a rise in plasma potassium concentration. The delineation of the separate contributions of these factors to the observed alterations in potassium transport was an additional aim of the present study.

A further controversial issue to which we have directed our attention concerns the kaliuretic effect of glucocorticoids, particularly in adrenalectomized animals. Although this phenomenon has been repeatedly documented using clearance techniques (16-21), only limited information is available on the specific effect of glucocorticoids on tubular transport function (14). In particular, it is unknown whether these agents stimulate tubular potassium secretion directly, or whether the observed kaliuresis is secondary to their marked stimulant effect on glomerular filtration, sodium excretion, and urinary flow rate.

It was thus the purpose of the present study to investigate the specific influence of three factors on potassium secretion by the distal tubule: $(a)$ an acute infusion of aldosterone, $(b)$ an acute rise in plasma potassium concentration in the absence of a simultaneous rise in plasma aldosterone, and $(c)$ an acute infusion of a potent glucocorticoid, dexamethasone. In addressing these three interrelated topics, we used an experimental design that allowed for clamping the plasma concentrations of both classes of adrenal corticosteroid hormones at basal levels, upon which an acute infusion of a specific agent could be superimposed. Furthermore, we studied the direct effect of these experimental maneuvers on tubular potassium transport, independent of associated changes in luminal fluid composition and flow rate, using a technique of continuous microperfusion, in vivo, of individual distal tubules. It was thus possible to define the specific, differential effects of acute elevations in the plasma concentrations of aldosterone, dexamethasone, and potassium on potassium secretion by the distal tubule, and to evaluate these effects in relation to simultaneously measured changes in urinary potassium excretion.

\section{Methods}

Experimental protocol (see Fig. 1). Experiments were performed on adult male Sprague-Dawley rats (Charles River Breeding Laboratories,

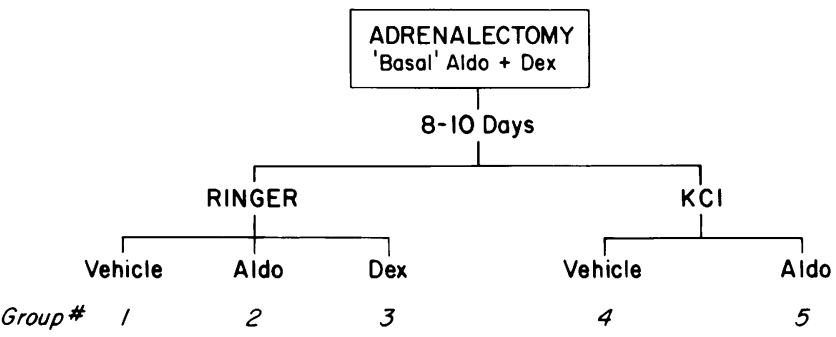

Figure 1. Experimental design. All animals received basal replacement doses of aldosterone (Aldo) and dexamethasone (Dex) via osmotic minipump inserted at the time of adrenalectomy. In addition, acute infusions of either aldo, dex, or vehicle were administered at the time of transport studies.

Inc., Boston, MA) ranging in weight from 210 to $250 \mathrm{~g}$. All animals were adrenalectomized via bilateral flank incisions under Nembutal anesthesia $(60 \mathrm{mg} / \mathrm{kg}$ body weight [bw] i.p.) 8-10 d before transport studies. At the time of adrenalectomy, an Alzet osmotic minipump (No. 2002, 14-d size, Alza Corp., Palo Alto, CA) was implanted subcutaneously in the neck of each rat. The pumps were loaded with a solution of $d$-aldosterone and dexamethasone (both from Sigma Chemical Co., St. Louis, MO) dissolved in polyethylene glycol 400 (J. T. Baker Chemical Co., Phillipsburg, NJ), so as to deliver aldosterone at $0.5 \mu \mathrm{g} / 100 \mathrm{~g}$ bw per $\mathrm{d}$, and dexamethasone at $1.2 \mu \mathrm{g} / 100 \mathrm{~g}$ bw per d. This replacement dose of aldosterone was chosen since it resembled the daily secretion rate in the rat (22), and resulted in plasma aldosterone levels similar to those measured in awake, unstressed rats on the same dietary intake (see Results). The dose of dexamethasone used has been found to maintain normal weight gain, normalize glomerular filtration rate (GFR),' and produce normal fasting plasma glucose and insulin concentrations in adrenalectomized rats (unpublished observations).

After adrenalectomy and minipump implantation, all animals were maintained in individual cages with free access to tap water, and fed $18 \mathrm{~g}$ daily of rat chow (No. 5010, Ralston Purina Co., Chicago, IL). This amount of chow was consumed completely by each rat, and provided a total daily $\mathrm{Na}$ and $\mathrm{K}$ intake of $\sim 2.9$ and $4.8 \mathrm{mmol}$, respectively. After 8-10 d, rats were divided randomly into five groups of six animals each for transport studies, as described below. In brief, groups 1-3 were designed to evaluate the effects of acute infusions of aldosterone and dexamethasone during normokalemia, while groups 4-5 examined the effect of hyperkalemia, with and without acute aldosterone infusion.

On the day of study, rats were anesthetized with Inactin (Byk Gluden, Konstanz, Federal Republic of Germany), $100 \mathrm{mg} / \mathrm{kg}$ bw i.p., then tracheostomized, and placed on a feedback-regulated table designed to keep body temperature constant at $37^{\circ} \mathrm{C}$. The right carotid artery was catheterized to allow for blood pressure monitoring and periodic blood sampling for measurement of hematocrit, inulin radioactivity, and plasma sodium and potassium concentrations. The left jugular vein was cannulated to allow for fluid administration and acute hormone infusions. The left kidney was prepared for micropuncutre as previously described from this laboratory $(15,23)$.

1. Abbreviations used in this paper: $\mathrm{A}$, aldosterone; $\mathrm{D}$, dexamethasone; GFR, glomerular filtration rate; K, high-K solution; R, Ringer solution; $\mathrm{V}$, vehicle. 
Immediately after insertion of the venous cannula, all rats were given a bolus of Ringer solution (R) $\left(\mathrm{Na}^{+}, 145 \mathrm{mM} ; \mathrm{K}^{+}, 5 \mathrm{mM} ; \mathrm{Cl}^{-}\right.$, $125 \mathrm{mM} ; \mathrm{HCO}_{3}^{-}, 25 \mathrm{mM}$ ) equivalent to $1 \%$ of body weight, followed by a continuous infusion of this fluid at a rate of $2 \mathrm{ml} / 100 \mathrm{~g}$ bw per $h$. In groups 1-3, this infusion was continued until completion of the experiment, a total time of $4 \mathrm{~h}$. In groups 4-5, the Ringer solution was replaced after $90 \mathrm{~min}$ by a high-K solution $(\mathrm{K})\left(\mathrm{Na}^{+}, 60 \mathrm{mM} ; \mathrm{K}^{+}\right.$, $90 \mathrm{mM}$; anions as before) designed to deliver an acute potassium load of $3 \mu \mathrm{mol} / 100 \mathrm{~g}$ bw per min for the subsequent 2.5-h period. Microperfusion and clearance studies were performed (as described below) in all experimental groups in the period from 2 to $4 \mathrm{~h}$ after insertion of the venous cannula.

In addition to the above fluid infusion, a second infusion was commenced in all rats at the time of venous cannulation. In groups 1 and 4 , this solution consisted of vehicle (V) only $(0.05 \%$ ethanol in Ringer solution), and was infused at $1 \mathrm{ml} / \mathrm{h}$. In groups 2 and 5 , this infusion contained aldosterone (A) so as to deliver $0.2 \mu \mathrm{g} / 100 \mathrm{~g} \mathrm{bw}$ per $\mathrm{h}$, initiated by a bolus of $0.2 \mu \mathrm{g} / 100 \mathrm{~g}$ bw. This protocol was intended to produce and maintain an acute rise in plasma aldosterone concentration similar to that seen in response to acute potassium infusion in intact rats (15). In group 3, this second infusion delivered dexamethasone (D) as the Na-phosphate salt Hexadrol (Organon Diagnostics, West Orange, NJ), at $0.2 \mu \mathrm{g} / 100 \mathrm{~g}$ bw per $\mathrm{h}$, after an initial bolus of $2 \mu \mathrm{g} / 100 \mathrm{~g}$. This dose was chosen in order to reproduce the kaliuretic response to dexamethasone injection described in the literature $(16,17,21)$. In all groups, the second infusion line also delivered [methoxy- ${ }^{3} \mathrm{H}$ ]inulin (New England Nuclear, Boston, MA) at $25 \mu \mathrm{Ci} / \mathrm{h}$; a priming dose of $25 \mu \mathrm{Ci}$ of this isotope was also included in the bolus of Ringer solution used to replace surgical fluid losses.

In all studies, transport data were obtained in the 2-h period commencing $120 \mathrm{~min}$ after initiation of acute hormone (or vehicle) infusion, so as to allow sufficient time for the biological effect of these steroids to be fully expressed (8). Two types of transport experiment were conducted simultaneously in each rat:

(a) Clearance experiments were conducted in order to define the overall effect of each infusion protocol on renal water and electrolyte excretion and GFR. This involved collection of three 40-min urine specimens from the ureter of the exposed kidney, together with samples of arterial blood before and after each urine sample.

(b) Continuous microperfusion of single superficial distal tubules, in vivo, was performed to study tubular ion and water transport under conditions of constant flow rate and sodium delivery. For this purpose, an artificial early distal fluid was used having the following composition: $\mathrm{NaCl}, 80 \mathrm{mM} ; \mathrm{KCl}, 2 \mathrm{mM} ; \mathrm{Na}_{2} \mathrm{HPO}_{4}, 1.5 \mathrm{mM} ; \mathrm{NaH}_{2} \mathrm{PO}_{4}, 3 \mathrm{mM}$; FDC Green dye (No. 2); $0.1 \%$ [ methoxy- ${ }^{3} \mathrm{H}$ ]inulin, $25 \mu \mathrm{Ci} / \mathrm{ml}$. Final $\mathrm{Na}^{+}$concentration was $86 \mathrm{mM} ; \mathrm{K}, 2.0 \mathrm{mM}$; osmolality, $162 \mathrm{mosmol} /$ $\mathrm{kg}$; $\mathrm{pH}$ 6.6. The technique used has been previously described in detail $(23,24)$, and involved pump-driven microperfusion from an early to a late segment of the same distal tubule. The perfusion rate achieved in vivo was calculated from the measured rate of fluid collection multiplied by the ratio of inulin concentrations in collected/perfused fluids. The mean rate of perfusion thus obtained was $12.3 \pm 0.1 \mathrm{nl} / \mathrm{min}$ (SEM, $n=72$ ), and there were no significant differences among the groups.

One to five distal tubules were perfused in the 2-h experimental period in each rat. After the experiment, every distal tubule studied was injected with Microfil silicone rubber compound (Canton Biomedical Products, Boulder, CO); the kidneys were macerated overnight in $25 \% \mathrm{NaOH}$, and at microdissection the following day, the position of the puncture sites and the perfused tubular length were determined. Tubular fluid collections were discarded if the early distal site did not lie in the proximal half of the segment between the macula densa and the first junction with another distal tubule, and if the late distal site lay outside the latter half of this segment. There were no differences in the mean localization of early distal and late distal sites punctured among the five groups studied.

At the conclusion of each experiment, a sample of arterial blood was taken for blood-gas analysis. In addition, plasma was obtained from half the animals in groups 1, 2, 4, and 5 for aldosterone assay. The remaining rats in these four groups were used for a morphological study of the contralateral (nonmicropunctured) kidney. The results of this study will be reported in a subsequent paper.

Analytic methods. Sodium and potassium concentrations were determined in plasma and urine by flame photometry (model 143, Instrumentation Laboratory, Inc., Lexington, MA), and in tubular fluid samples by helium-glow spectrophotometry (American Instrument Co., Silver Spring, MD). $\left[{ }^{3} \mathrm{H}\right]$ inulin radioactivity was measured by liquid scintillation counting (Searle Analytical 92; G. D. Searle Co., Stokie, IL) in a $77 \%$ solution of Hydrofluor (National Diagnostics, Inc., Somerville, NJ). Urine volumes were estimated gravimetrically, and microperfusion sample volumes were measured in a calibrated constant bore capillary. Arterial $\mathrm{pH}$ and $\mathrm{pCO}_{2}$ were determined on a blood gas analyzer (model 213-329, Instrumentation Laboratory, Inc.), and plasma $\mathrm{HCO}_{3}^{-}$was calculated from these values using the Henderson-Hasselbalch equation. Plasma aldosterone was kindly measured by radioimmunoassay by Dr. Patrick Mulrow.

Calculations. GFR and fractional electrolyte excretion rates were determined from clearance data using standard formulae. For clearance studies, a single value for each measured variable was obtained in a given animal by averaging the three consecutive 40 -min values; results reported represent the mean of these data for all animals studied under a given set of infusion conditions ( $n=$ number of rats). In microperfusion studies, net water flux $\left(J_{v}\right)$ across single distal tubules was determined as the difference between calculated perfusion rate (see above) and collection rate. Net tubular transport of sodium $\left(\mathrm{J}_{\mathrm{Na}_{\mathrm{a}}}\right)$ and potassium $\left(J_{K}\right)$ were calculated from the amount of each ion delivered by the perfusion pipette minus the amount collected by the collection pipette (25). Net fluxes are thus positive for reabsorption and negative for secretion. Results for ion or water transport from all tubules perfused under a given set of conditions were pooled to obtain the mean values reported ( $n=$ number of tubules).

Statistical analysis involved a preliminary inspection of the data using a one-way analysis of variance. If there was a significant difference $(P<0.05)$ among the means, the least significant difference test $(26)$ was used to evaluate the statistical significance between particular mean values. $P$ values reported in the text are based on least significant difference comparisons (given as $P<0.05$ and $P<0.01$ only). In the case of some parameters (urinary sodium excretion and flow rate) in which large differences in variance were noted among the groups, the above statistical evaluations were performed after applying a logarithmic transformation to the data (26). All data are expressed as means \pm SEM.

\section{Results}

Systemic parameters. Table I gives the data for the analyses performed on peripheral arterial plasma during each of the five experimental protocols. In general, the hematocrit and 
Table I. Systemic Parameters

\begin{tabular}{lccccc}
\hline & $\begin{array}{l}\text { Group 1 } \\
\mathrm{R}+\mathrm{V}\end{array}$ & $\begin{array}{l}\text { Group 2 } \\
\mathrm{R}+\mathrm{A}\end{array}$ & $\begin{array}{l}\text { Group 3 } \\
\mathrm{R}+\mathrm{D}\end{array}$ & $\begin{array}{c}\text { Group 4 } \\
\mathrm{K}+\mathrm{V}\end{array}$ & $\begin{array}{l}\text { Group 5 } \\
\mathrm{K}+\mathrm{A}\end{array}$ \\
\hline $\mathrm{BP}(\mathrm{mmHg})$ & $123 \pm 1$ & $126 \pm 1$ & $124 \pm 4$ & $120 \pm 2$ & $120 \pm 2$ \\
Hematocrit $(\%)$ & $45.2 \pm 0.8$ & $45.6 \pm 0.4$ & $41.6 \pm 1.2$ & $46.0 \pm 0.9$ & $44.6 \pm 1.6$ \\
Plasma $\left[\mathrm{Na}^{+}\right](m M)$ & $149 \pm 2$ & $148 \pm 1$ & $144 \pm 1$ & $142 \pm 1$ & $145 \pm 1$ \\
Plasma $\left[\mathrm{K}^{+}\right](m M)$ & $5.0 \pm 0.1$ & $4.9 \pm 0.1$ & $4.7 \pm 0.1$ & $7.3 \pm 0.2$ & $7.6 \pm 0.1$ \\
pH & $7.45 \pm 0.01$ & $7.44 \pm 0.01$ & $7.45 \pm 0.01$ & $7.46 \pm 0.02$ & $3.45 \pm 0.01$ \\
$\mathrm{pCO}_{2}(\mathrm{mmHg})$ & $36.6 \pm 1.8$ & $37.4 \pm 2.2$ & $35.8 \pm 1.6$ & $34.6 \pm 0.9$ & 24.1 \\
{$\left[\mathrm{HCO}_{3}\right](m M)$} & $24.4 \pm 0.8$ & $25.0 \pm 0.8$ & $24.1 \pm 0.9$ & $24.3 \pm 1.0$ & \\
\hline
\end{tabular}

Values are means \pm SEM, $n=$ six rats per group. Group headings are explained in text. BP, mean arterial blood pressure.

plasma sodium concentration were similar among the groups, although animals treated with acute dexamethasone (group 3) had a lower mean hematocrit and plasma sodium than the other Ringer solution-infused groups $(P<0.05$ in each case). Plasma potassium concentration was significantly higher in the groups of animals infused with the high-K solution (groups 4 and 5) than in Ringer solution-infused groups $(P<0.01)$. Furthermore, the plasma potassium reached a significantly higher level in group $4(\mathrm{~K}+\mathrm{V})$ than in group $5(\mathrm{~K}+\mathrm{A})$ $(P<0.01)$.

The acid-base status of animals in all groups, as reflected in arterial $\mathrm{pH}$ and $\mathrm{pCO}_{2}$ measurements taken at the end of each experiment, was similar, showing a mild respiratory alkalosis in each case. Mean arterial blood pressure, recorded for the duration of all transport experiments, was also unaffected by the various experimental maneuvers, averaging $123 \pm 1$ $\mathrm{mmHg}$ for the 30 animals studied.

Plasma aldosterone concentrations. There were no differences in the mean plasma aldosterone levels measured in groups of rats given basal aldosterone replacement by minipump, whether or not plasma potassium was elevated. Thus, results for these groups have been pooled. The mean plasma aldosterone was $4.4 \pm 1.9 \mathrm{ng} / \mathrm{dl}(n=16)$ (includes values obtained in additional rats used in preliminary clearance studies, which were treated the same way as groups 1 and 4), a value not significantly different from that obtained in unstressed awake rats in this laboratory $(7.2 \pm 1.3 \mathrm{ng} / \mathrm{dl})$. Similarly, the two groups of animals infused acutely with aldosterone had similar plasma aldosterone concentrations, regardless of whether or not they also received an acute potassium load. The pooled mean value for these groups (2 and 5) was $55.8 \pm 11.5 \mathrm{ng} / \mathrm{dl}$, a value similar to that measured in intact rats after a comparable potassium infusion $(60 \pm 4 \mathrm{ng} / \mathrm{dl})(15)$.

Clearance experiments. Data on whole kidney fluid and electrolyte excretion and GFR are given in Table II. Animals infused with vehicle or aldosterone (groups 1, 2, 4, 5) had similar GFRs, but group 3 rats, infused with dexamethasone, achieved a significantly higher mean GFR $(0.55 \pm 0.03 \mathrm{ml} / \mathrm{min}$ per $100 \mathrm{~g})$ than all other groups $(P<0.01)$.

Final urinary flow rate was significantly lowered by aldosterone infusion during normokalemia $(P<0.05$, group 2 vs. group 1); during hyperkalemia (groups 4 and 5), this flow rate reduction failed to reach statistical significance. Infusion of potassium at constant aldosterone levels (group 4 vs. group 1,

Table II. Clearance Data

\begin{tabular}{lccccc}
\hline & $\begin{array}{c}\text { Group 1 } \\
\mathrm{R}+\mathrm{V}\end{array}$ & $\begin{array}{l}\text { Group 2 } \\
\mathrm{R}+\mathrm{A}\end{array}$ & $\begin{array}{l}\text { Group 3 } \\
\mathrm{R}+\mathrm{D}\end{array}$ & $\begin{array}{l}\text { Group 4 } \\
\mathrm{K}+\mathrm{V}\end{array}$ & $\begin{array}{l}\text { Group 5 } \\
\mathrm{K}+\mathrm{A}\end{array}$ \\
\hline $\mathrm{GFR}(\mathrm{ml} / \mathrm{min} / 100 \mathrm{~g})$ & $0.38 \pm 0.01$ & $0.43 \pm 0.03$ & $0.55 \pm 0.03$ & $0.35 \pm 0.03$ & $0.41 \pm 0.02$ \\
$\mathrm{~V}(\mu \mathrm{l} / \mathrm{min} / 100 \mathrm{~g})$ & $3.5 \pm 0.5$ & $1.8 \pm 0.3$ & $11.7 \pm 3.3$ & $7.5 \pm 1.0$ & $5.6 \pm 0.6$ \\
$\mathrm{Urine}[\mathrm{Na}+](\mathrm{mM})$ & $100.2 \pm 9.6$ & $41.4 \pm 10.8$ & $152.0 \pm 16.8$ & $48.2 \pm 13.3$ & $15.7 \pm 3.6$ \\
$\mathrm{U}_{\mathrm{Na}} \mathrm{V}(\mu \mathrm{mol} / \mathrm{min} / 100 \mathrm{~g})$ & $0.37 \pm 0.08$ & $0.08 \pm 0.03$ & $1.64 \pm 0.40$ & $0.38 \pm 0.14$ & $0.09 \pm 0.02$ \\
$\mathrm{FE}_{\mathrm{Na}}(\%)$ & $0.66 \pm 0.13$ & $0.13 \pm 0.04$ & $2.04 \pm 0.48$ & $0.71 \pm 0.19$ & $0.15 \pm 0.04$ \\
$\mathrm{Urine}_{\mathrm{N}}\left[\mathrm{K}^{+}\right](\mathrm{mM})$ & $182.8 \pm 13.8$ & $273.1 \pm 26.2$ & $107.3 \pm 21.3$ & $167.8 \pm 9.4$ & $235.1 \pm 17.2$ \\
$\mathrm{U}_{\mathrm{K}} \mathrm{V}(\mu \mathrm{mol} / \mathrm{min} / 100 \mathrm{~g})$ & $0.55 \pm 0.07$ & $0.46 \pm 0.05$ & $0.81 \pm 0.07$ & $1.21 \pm 0.11$ & $1.25 \pm 0.11$ \\
$\mathrm{FE}_{\mathrm{K}}(\%)$ & $29.2 \pm 3.1$ & $22.7 \pm 3.0$ & $32.3 \pm 3.4$ & $48.4 \pm 4.3$ & $46.0 \pm 5.0$
\end{tabular}

Values are means \pm SEM, $n$ = six rats per group. Group headings are as in Table I. V, urine flow rate; $U_{\mathrm{Na}} \mathrm{V}, \mathrm{U}_{\mathrm{K}} \mathrm{V}$, total urinary sodium and potassium excretion, respectively; $\mathrm{FE}_{\mathrm{Na}}, \mathrm{FE}_{\mathrm{K}}$, fractional urinary sodium and potassium excretion, respectively. 
and group 5 vs. group 2) increased fluid excretion over that seen during Ringer solution infusion $(P<0.01$ in both cases). Acute infusion of dexamethasone during normokalemia (group 3) markedly stimulated urinary flow rate above that obtained in all other groups $(P<0.01)$.

Absolute and fractional excretion of sodium were significantly reduced by acute aldosterone, both during Ringer solution and $\mathrm{KCl}$ infusions $(P<0.01$ in each case). Dexamethasone, on the other hand, stimulated sodium excretion above that obtained in the other four groups $(P<0.01)$. Urinary sodium concentrations in animals in groups 1-4 were generally $>35 \mathrm{mM}$; however, during aldosterone infusion in hyperkalemic rats (group 5) urinary sodium concentration was reduced on average to $15.7 \pm 3.6 \mathrm{mM}(P<0.05$ compared with group $4, K+V$ ), a value that may be limiting to the potassium secretory apparatus of the distal tubule and cortical collecting ducts $(27,28)$.

A noteworthy feature of these clearance results is the lack of significant effect on absolute or fractional potassium excretion of acute aldosterone infusion, both during normokalemia (group 2 vs. group 1) and hyperkalemia (group 5 vs. group 4). In both cases, however, the urine to plasma potassium concentration ratio was significantly increased by aldosterone $(P<0.01$ and $P<0.05$, respectively). In contrast, acute dexamethasone infusion significantly stimulated absolute (though not fractional) potassium excretion by some $50 \%$ in Ringer-infused animals (group 3 vs. group $1, P<0.05$ ), while causing at the same time a reduction in the urine to plasma potassium concentration ratio measured in the same experiments $(P<0.05)$. Potassium infusion at either low (groups 1 and 4) or high (groups 2 and 5) aldosterone levels produced a significant increase in both absolute and fractional potassium excretion $(P<0.01$ in each case $)$.

To gain further insight into the factors influencing renal potassium excretion under the conditions of these experiments, data for urinary potassium excretion in individual animals were plotted against the final urinary flow rate achieved in the same study. As shown in Fig. 2, when points were grouped according to whether the circulating aldosterone level was basal (groups 1 and 4) or high (groups 2 and 5), the data in both groups were well-fitted by linear regressions, each having a highly significant correlation coefficient $(P<0.001$ in both cases). Of particular interest, however, was the finding that the slope of this relationship at high aldosterone levels was significantly greater $(P<0.01)$ than at low aldosterone levels. Thus, while consistent with the well-established influence of flow rate on distal tubular potassium secretion, this analysis suggests that the circulating aldosterone concentration can modify the steepness of the relationship between these two variables.

Microperfusion experiments. It is clear from the above clearance data that under spontaneous free-flow conditions, infusion of hormone or potassium solutions resulted in changes in several factors, particularly urinary flow rate and sodium concentration, which can themselves influence potassium se-

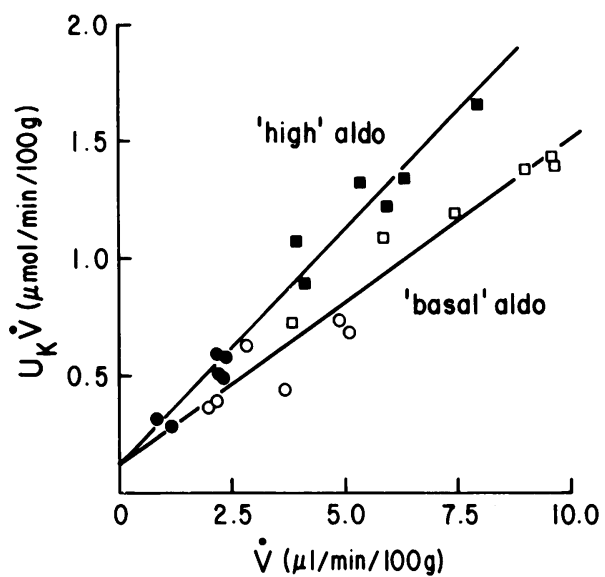

Figure 2. Relationship between urinary potassium excretion $\left(U_{K} \dot{V}\right)$ and final urinary flow rate $(\dot{V})$ in clearance studies. Each symbol represents a single experiment ( $\mathrm{O}$ and $\square$, vehicle-infused animals receiving Ringer solution or $\mathrm{KCl}$, respectively; $\bullet$ and $\bullet$, aldosteroneinfused animals receiving Ringer solution or $\mathrm{KCl}$, respectively). Regression equation for 'basal' aldosterone (aldo) line: $y=0.14 x$ $+0.11, r=0.97$; for 'high' aldo line: $y=0.20 x+0.11, r=0.98$ (slopes significantly different, $P<0.01$ ).

cretion along the distal nephron (11). To define the specific effects of infusions of aldosterone, dexamethasone, and potassium on tubular potassium transport, independent of changes in these luminal conditions, we performed simultaneous experiments in all five groups of rats using the technique of continuous microperfusion, in vivo, of individual distal tubules, using a constant perfusion fluid and flow rate. The results of these experiments are shown in Table III. A total of 72 distal tubules were perfused in the 30 rats studied. There were no significant differences in perfusion rate or tubular fluid reabsorption, $\mathrm{J}_{\mathrm{v}}$, among the groups.

In sharp contrast to the results from the clearance experiments, microperfusion data clearly revealed a significant effect of acute aldosterone infusion on potassium secretion. Thus, under conditions of systemic Ringer solution infusion, aldosterone almost doubled net tubular potassium secretion, from $62 \pm 8$ to $113 \pm 6 \mathrm{pmol} / \mathrm{min}$ (group 1 vs. group $2, P<0.01$ ), and a similar effect of aldosterone was also noted during potassium infusion (group 4 vs. group $5, P<0.01$ ). Dexamethasone, on the other hand, was without effect on net tubular potassium secretion under conditions of constant luminal flow rate (group 3 vs. group 1). The effect of hyperkalemia per se, at constant luminal flow rate and systemic aldosterone levels, can be assessed by comparing group 4 vs. group 1 (basal aldosterone), and group 5 vs. group 2 (elevated aldosterone). It is clear that in both cases, increased plasma $\mathrm{K}$ is associated with stimulation of tubular potassium secretion $(P<0.01$ in each case).

The relationship between the mean results for tubular potassium secretion and plasma potassium concentration under 
Table III. Microperfusion Data

\begin{tabular}{lccccc}
\hline & $\begin{array}{l}\text { Group 1 } \\
\mathrm{R}+\mathrm{V}\end{array}$ & $\begin{array}{l}\text { Group 2 } \\
\mathrm{R}+\mathrm{A}\end{array}$ & $\begin{array}{l}\text { Group 3 } \\
\mathrm{R}+\mathrm{D}\end{array}$ & $\begin{array}{l}\text { Group 4 } \\
\mathrm{K}+\mathrm{V}\end{array}$ & $\begin{array}{l}\text { Group 5 } \\
\mathrm{K}+\mathrm{A}\end{array}$ \\
\hline Perfusion rate $(\mathrm{nl} / \mathrm{min})$ & $11.7 \pm 0.3$ & $12.4 \pm 0.4$ & $12.3 \pm 0.3$ & $12.6 \pm 0.3$ & $12.5 \pm 0.3$ \\
Inulin ratio & $1.23 \pm 0.04$ & $1.17 \pm 0.03$ & $1.10 \pm 0.03$ & $1.15 \pm 0.02$ & $1.15 \pm 0.02$ \\
$\mathrm{~J}_{\mathrm{v}}(\mathrm{nl} / \mathrm{min})$ & $2.1 \pm 0.3$ & $1.7 \pm 0.2$ & $1.1 \pm 0.3$ & $1.6 \pm 0.1$ & $1.5 \pm 0.02$ \\
Collected $\left[\mathrm{Na}^{+}\right](\mathrm{mM})$ & $84.2 \pm 1.8$ & $85.8 \pm 1.6$ & $78.0 \pm 1.9$ & $91.4 \pm 0.9$ & $87.6 \pm 0.9$ \\
$\mathrm{~J}_{\mathrm{Na}}(\mathrm{pmol} / \mathrm{min})$ & $166.0 \pm 26.6$ & $129.9 \pm 18.7$ & $151.3 \pm 29.0$ & $70.2 \pm 10.8$ & $98.4 \pm 13.9$ \\
Collected $\left[\mathrm{K}^{+}\right](\mathrm{mM})$ & $8.8 \pm 0.7$ & $13.0 \pm 0.6$ & $7.8 \pm 0.4$ & $14.5 \pm 0.5$ & $17.7 \pm 0.6$ \\
$\mathrm{~J}_{\mathrm{K}}(\mathrm{pmol} / \mathrm{min})$ & $-61.8 \pm 7.6$ & $-113.1 \pm 6.3$ & $-63.9 \pm 5.6$ & $-130.7 \pm 4.5$ & $-167.8 \pm 7.4$ \\
Perfused length $(\mathrm{mm})$ & $1.2 \pm 0.0$ & $1.2 \pm 0.1$ & $1.3 \pm 0.1$ & $1.2 \pm 0.1$ & $1.2 \pm 0.0$ \\
& & & & & \\
\hline
\end{tabular}

Values are means \pm SEM, $n=12-17$ tubules per group. Group headings are as in Table I. Inulin ratio = inulin counts in collected fluid/perfused fluid. $\mathrm{J}_{\mathrm{v}}, \mathrm{J}_{\mathrm{Na}}, \mathrm{J}_{\mathrm{K}}$, net transepithelial fluxes of water, sodium, and potassium, respectively (positive values, reabsorption; negative values, secretion).

the five experimental conditions studied is shown in Fig. 3. All groups studied during Ringer solution infusion (groups 1-3) achieved similar plasma potassium concentrations; under these conditions, simultaneous infusion of aldosterone, but not dexamethasone, stimulated potassium secretion considerably above control levels. During potassium infusion (groups 4 and 5), plasma potassium was elevated, although to a lesser degree during simultaneous aldosterone infusion (group 5) than during vehicle infusion (group 4). Despite this difference, aldosterone infusion during hyperkalemia was associated with a greater stimulation of tubular potassium secretion than hyperkalemia alone.

One further implication of the lower plasma potassium concentration achieved during aldosterone infusion after acute potassium loading should be noted. Since absolute potassium excretion was not different between these two groups (groups

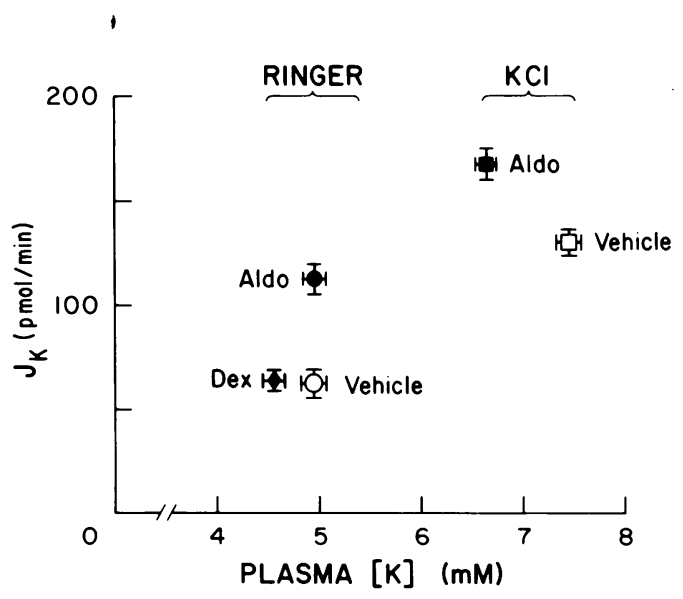

Figure 3. Potassium secretion by microperfused distal tubules $\left(\mathrm{J}_{\mathrm{K}}\right)$ as a function of mean plasma potassium concentration. Mean data ( \pm SEM) for the three groups studied during Ringer solution infusion, and the two groups studied during $\mathrm{KCl}$ infusion are shown by different symbols.
4 and 5, Table II), it may be inferred that extrarenal uptake of potassium, and hence potassium tolerance, was enhanced during acute aldosterone infusion.

Data on tubular reabsorption of sodium (Table III) showed a much greater variation within individual groups than did potassium transport data. Infusion of aldosterone was not associated with a significant change in sodium reabsorption in the perfused segments, during either Ringer solution or potassium protocols. Dexamethasone treatment was similarly without effect on sodium transport compared with vehicle-infused controls. It is noteworthy, however, that infusion of potassium at constant (basal) aldosterone levels (group 4 vs. group 1) resulted in a significant inhibition of tubular sodium reabsorption $(70.2 \pm 10.8$ vs. $166.0 \pm 26.6 \mathrm{pmol} / \mathrm{min}, P<0.01)$.

\section{Discussion}

The purpose of this study was to examine, at the level of the distal tubule as well as the whole kidney, the specific, differential effects on renal potassium transport of three acutely administered agents: aldosterone, dexamethasone, and potassium. Two design features allowed us to achieve this aim: (a) use of adrenalectomized rats prepared with basal hormone replacement, so that the separate effects of acute infusions of each agent could be studied on a physiological base line; and $(b)$ use of tubular microperfusion techniques to allow transport effects to be defined in the absence of secondary alterations in luminal fluid composition and flow rate.

The principal results of the simultaneous clearance and microperfusion experiments performed in this study are summarized side-by-side in Fig. 4. Only acute aldosterone infusion and hyperkalemia directly stimulated distal tubular potassium secretion when luminal flow was held constant by microperfusion, whereas under these conditions acute dexamethasone had no effect on tubular potassium transport. On the other hand, final urinary flow rate fell during aldosterone infusion, but rose during infusion of dexamethasone or potassium. The 

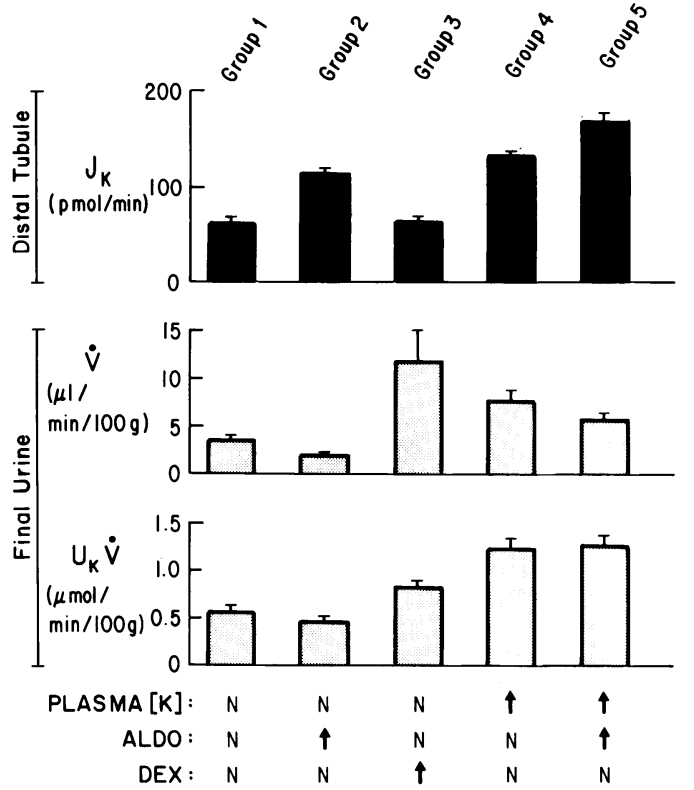

Figure 4. Summary of principal results of simultaneous microperfusion experiments (distal tubular potassium secretion, $\mathrm{J}_{\mathrm{K}}$, top) and clearance experiments (urinary flow rate, $\mathrm{V}$, and potassium excretion, $\mathrm{U}_{\mathrm{K}} \mathrm{V}$, middle and lower, respectively) in each of the five experimental groups studied. The conditions prevailing in each group are shown at the foot of the figure: $N$ represents normal (for plasma $\mathrm{K}$ ), or basal (for hormone levels). ALDO, aldosterone; DEX, dexamethasone.

net effect of these influences on renal potassium transport was to cause no overall change in final potassium excretion after acute aldosterone, but to induce a mild kaliuresis after acute dexamethasone and a marked kaliuresis during acute potassium infusion.

Effect of acute aldosterone infusion. Acute elevation of plasma aldosterone levels was associated in these experiments with increased total renal sodium reabsorption, but no change in potassium excretion. This absence of a kaliuretic response to acute aldosterone infusion, while at variance with classical accounts of the effects of this hormone (1), has been previously noted by numerous investigators $(16,29-31)$. Indeed, a recent extensive review of the literature pertaining to this question (6) failed to produce convincing evidence for an important role for aldosterone, given in small amounts and under appropriate physiological conditions, in regulating renal potassium excretion. However, a limited number of micropuncture studies $(12,13,30,32,33)$, as well as data from isolated perfused cortical collecting tubules $(28,34)$, suggest that aldosterone does influence epithelial potassium secretion in distal nephron segments. The present experiments provide a possible explanation for this paradox. Aldosterone infusion was associated with a marked reduction in sodium excretion, and hence in urinary flow rate, particularly during Ringer solution experiments. It is well established that flow rate of luminal fluid through the distal tubule is one of the prime determinants of distal potassium secretion (11). We therefore considered it possible that any direct stimulatory effect of aldosterone on potassium secretion was being masked under these conditions by an opposing fall in flow along the distal portions of the nephron where aldosterone is known to act. This hypothesis was tested and confirmed by our microperfusion experiments. When distal tubules were microperfused at a constant rate in all experimental groups, potassium secretion per tubule was stimulated by acute aldosterone, both at normal and elevated plasma potassium concentrations. Thus, the net result of a direct hormone-mediated stimulation of tubular potassium secretion, opposed by a secondary flow-mediated inhibition of this process, resulted in no overall change in final urinary potassium excretion (see Fig. 4).

A second factor that may act to obscure the aldosterone effect on potassium transport in some of these studies is the luminal fluid sodium concentration. Although potassium secretion is generally independent of this quantity over a wide physiological range (27), it has been demonstrated, both for the distal tubule (27) and the cortical collecting duct (28), that potassium secretion is inhibited when luminal sodium concentration is reduced below $\sim 35 \mathrm{mM}$ in tubules perfused at constant flow rate. No estimates of luminal fluid sodium concentration in cortical tubules during these experiments are available, since free-flow micropuncture collections were not performed. However, the final urinary sodium concentration of $16 \mathrm{mM}$ obtained during aldosterone infusion in hyperkalemic rats (group 5) was clearly below the critical range of 35-40 $\mathrm{mM}$ at which potassium secretion further upstream may be limited, and was significantly lower than in the corresponding control group (48 $\mathrm{mM}$ in group 4). Thus, in this situation, reduced luminal sodium availability may have been an important factor preventing expression of the aldosterone effect on potassium transport in the final urine.

It was noted earlier that when aldosterone has been found in previously reported studies to cause an acute kaliuresis, it has usually been in the context of either some degree of sodium-loading $(33,35,36)$, or of potassium-depletion (18, 29, 30). For example, one recent report (35) found an absence of kaliuresis after acute aldosterone administration in animals receiving minimal amounts of sodium during clearance studies, which contrasted with a kaliuretic response if sodium was provided freely during the study as well as in the 24-h-period before study. Fractional sodium excretion in these latter groups ranged from 1.0 to $>3.0 \%$, compared with $0.7 \%$ or less in the current study. In line with the arguments presented above, it is likely that sodium loading permits expression of aldosteroneinduced kaliuresis by minimizing the antidiuretic effect associated with a reduction in sodium excretion after aldosterone, and/or by preventing falls in urinary sodium concentration to very low levels (see above). Nonetheless, in physiological terms, it would appear more meaningful to consider the acute actions of aldosterone in the context in which they are likely to occur in nature, namely, under conditions of low sodium excretion, as in the present study. 
A similar explanation may underlie the observation that kaliuresis often follows aldosterone administration in potassiumdepleted animals $(18,29,30)$. As previously shown from our laboratory (37), the flow dependence of urinary potassium excretion is virtually lost in rats subjected to a period of dietary potassium depletion. Hence, under these circumstances, the drop in urinary flow rate after aldosterone administration would be ineffective in attenuating potassium secretion, thus leaving unopposed the direct stimulatory effect on tubular potassium secretion to be expressed in the final urine. Again, however, it may be argued that potassium loading, rather than depletion, represents a more physiological context in which to consider aldosterone action.

It is also appropriate to consider here the relationship of the current findings to the effects of chronic aldosterone exposure on potassium excretion. It is well established in clinical $(4,5)$ as well as laboratory $(2,3)$ experience that potassium depletion, due primarily to increased urinary potassium excretion, follows continued exposure to excess mineralocorticoid hormone. The fact that this goes on after escape from the sodium-retaining effects of these agents has occurred has been used as an argument for separate mechanisms of action of aldosterone on sodium reabsorption and potassium secretion (1). A more likely explanation is suggested from the results of the present study. Since escape from the antinatriuretic effect is related to plasma volume expansion and inhibition of proximal tubular sodium and water reabsorption $(2,38)$, it would be expected that initially depressed distal tubular and final urinary flow rates would be restored in this phase to normal or above-normal levels. When this occurs, the kaliuretic effect of aldosterone becomes apparent because the opposing influence of reduced flow rate has been removed. Thus, a period of urinary potassium loss ensues until balance is reestablished at a new, lower level of body potassium.

The present investigation has not studied directly the cellular sites or mechanisms of action of aldosterone on potassium secretion by the distal tubule. However, recently published information on the distribution of aldosterone receptors in the rat kidney (39), as well as on morphological $(40,41)$ and electrophysiological (42) consequences of aldosterone administration, are consistent with our finding of a specific transport effect of aldosterone in the distal tubular segment studied by microperfusion. ${ }^{2}$ Furthermore, evidence is available for both acute $(31,43)$ and chronic $(44)$ stimulatory

2. It should be noted here that the effect of aldosterone on renal sodium reabsorption, while clearly evident from our clearance data, was not demonstrated at the level of the distal tubule in microperfusion experiments. Two factors may explain this discrepancy: $(a)$ There was considerably greater tubule-to-tubule variation in sodium reabsorption than in potassium secretion rates. (b) A relatively smaller change would be predicted in sodium than potassium fluxes in the segment perfused, since only that moiety of sodium reabsorbed in the latter part of the accessible distal tubule (initial collecting tubule) is sensitive to aldosterone, whereas all of distal tubular potassium secretion occurs in this hormone-sensitive region (25). effects of mineralocorticoids on Na-K-ATPase activity in cortical collecting tubules, a change that presumably reflects an increase in transport activity in this segment. Nonetheless, no previous report has directly documented a specific effect of acute aldosterone administration on potassium secretion by an epithelium of the distal nephron, in vivo or in vitro.

Effect of acute hyperkalemia. In a previous study (15), we examined the effect of acute potassium infusion on the transport of potassium by the whole kidney and distal tubule in the intact rat. By using a microperfusion technique, it was possible in that study to demonstrate that the increased secretion of potassium by the distal tubule during acute hyperkalemia was independent of the enhanced distal delivery of fluid and sodium that potassium infusion induces, secondary to inhibition of proximal sodium reabsorption. It was not possible, however, to determine the separate contributions to the distal tubular response of hyperkalemia per se, and elevated plasma aldosterone concentration, since the increase in plasma potassium invariably stimulated adrenal aldosterone release. This question has been directly addressed in the present experiments, where the independent effect of hyperkalemia could be examined while aldosterone was clamped at basal levels by experimental design (group 4 compared with group 1). It is clear that hyperkalemia itself was associated with a marked stimulation of tubular potassium secretion under these conditions, possibly by activation of basolateral Na-K ATPase in distal cells and elevation of cellular potassium concentration (11). A further significant augmentation in potassium secretion was obtained by acute aldosterone infusion during hyperkalemia (group 5 vs. group 4).

It is possible to make a semiquantitative comparison between the present results and those obtained previously in our laboratory in intact rats (15) in order to estimate the relative importance of elevations in plasma potassium and aldosterone concentration in augmenting distal potassium secretion during acute potassium loading. In both cases the maximal increase in secretion between control and hyperkalemic states (group 5 vs. group 1 in the present study) was $\sim 100 \mathrm{pmol} / \mathrm{min}$. The present data suggest that somewhat more than half of this increase (69 of $106 \mathrm{pmol} / \mathrm{min}$ ) was due to the elevated plasma $\mathrm{K}$ concentration, and the remainder to the rise in aldosterone.

A further important corollary of the present results in relation to acute potassium loading is inherent in the potassium clearance data (Table II). Since potassium excretion was not enhanced by acute aldosterone during hyperkalemia (group 5 vs. group 4), it may be deduced that maximal rates of renal clearance of an acute potassium load do not require an associated acute increase in circulating aldosterone above basal levels. By inference, the rise in potassium excretion seen in intact rats after potassium infusion (15) is largely due to the increase in plasma potassium concentration, together with the effect of increased urinary flow rate (see above). The question arises then as to the purpose of the acute rise in plasma aldosterone in this situation. The answer is probably provided 
by the data for plasma potassium concentration in the two potassium-infused groups. The plasma potassium reached a significantly lower value in rats given acute aldosterone (group 5) than in those receiving vehicle (group 4), despite identical potassium loads in the two groups. Since total potassium excretion was also equal in the two groups (assuming that the unexposed kidney behaved similarly to the micropunctured kidney), it can be concluded that acute aldosterone infusion significantly enhanced uptake of potassium by extrarenal tissues, thus improving the animal's "tolerance" of the acute potassium load. This property of aldosterone has recently received increased attention in the literature $(3,45)$. It should be noted that this effect made it difficult, using the present experimental design, to assess the acute influence of aldosterone on potassium excretion at a constant, elevated plasma potassium concentration. Indeed, we have not excluded the possibility that a higher rate of potassium clearance might be produced by acute aldosterone if a fall in plasma potassium is prevented.

Effect of acute dexamethasone. The ability of an acute infusion of glucocorticoid hormones to stimulate urinary potassium excretion has been recognized for many years (19-21). Recently, this subject has been reexamined, and attention has been drawn to the differences between this glucocorticoid-type of kaliuresis and that classically associated with mineralocorticoid activity $(16,18)$. In particular, it has been noted that glucocorticoid kaliuresis is often accompanied by increases in GFR, urinary flow rate, and sodium excretion, which do not occur after mineralocorticoids. Because these changes may in themselves be indirectly responsible for stimulating potassium excretion after glucocorticoids, it has not been possible from clearance-type studies to determine whether these agents also have a direct influence on the tubular potassium transport mechanism.

The present studies have been able to provide an answer to this question by examining potassium transport by distal tubules microperfused at a constant rate in the absence and presence of an acute infusion of dexamethasone (group 3 vs. group 1). The dose used, similar to that previously reported in this context $(16,17,21)$, reproduced the kaliuresis described by others at the level of the final urine, but had no effect on the amount of potassium secretion measured in distal tubules studied under conditions of controlled luminal flow rate. From these results we conclude that increased potassium excretion after dexamethasone is a consequence of increased rates of fluid delivery into the distal tubule, secondary to improvement in GFR, ${ }^{3}$ rather than being a direct effect on the tubule itself. This is consistent with an earlier micropuncture study (14)

3. Another possible factor contributing to increased distal flow after dexamethasone is a decrease in fluid reabsorption from the distal tubule, a well-described effect of glucocorticoids (46). However, although fluid reabsorption $\left(\mathrm{J}_{\mathrm{V}}\right)$ after acute dexamethasone was approximately one-half that in the control group in the present study (Table III), this difference did not reach statistical significance by analysis of variance.

\begin{tabular}{lcc|c} 
& DIRECT & FLOW & NET \\
\hline Aldosterone & $\uparrow$ & $\downarrow$ & - \\
Dexamethasone & - & $\uparrow$ & $\uparrow$ \\
Hyperkalemia & $\uparrow$ & $\uparrow$ & $\uparrow \uparrow$ \\
\hline
\end{tabular}

Figure 5. Schematic outline of mechanisms whereby acute infusions of aldosterone, dexamethasone, and potassium affect renal potassium transport.

showing that the depressed transepithelial potassium concentration gradient in the late distal tubule of adrenalectomized rats could not be normalized by dexamethasone. Furthermore, both morphological (47) and biochemical (48) observations support the proposal that the transport functions of the distal nephron are under mineralocorticoid rather than glucocorticoid control.

In summary, we have performed experiments designed to test the independent effects of acute administration of aldosterone, dexamethasone, and potassium on renal potassium transport. To distinguish between secondary effects of these agents on potassium excretion, mediated largely by changes in tubular flow rate, and direct effects on the epithelial potassium secretory mechanism, we simultaneously studied potassium transport by clearance techniques and by microperfusion of single distal tubules, in vivo, at a constant rate. A schematic tabulation of the principal conclusions from these studies is shown in Fig. 5. Aldosterone was found to directly stimulate distal tubular potassium secretion, but since whole kidney urinary flow rate was reduced, in parallel with increased sodium reabsorption, there was no net effect on final urinary potassium excretion. In contrast, dexamethasone had no direct effect at the tubular level, but markedly stimulated urinary flow, resulting secondarily in increased net potassium excretion. Finally, hyperkalemia was itself a potent direct stimulus to tubular potassium secretion, but had an additional stimulatory effect by inducing increased urinary flow rates, resulting in markedly elevated final rates of urinary potassium excretion.

\section{Acknowledgments}

We are grateful to Dr. Patrick Mulrow for performing the plasma aldosterone measurements, and to Dr. Robert W. Berliner for a critical reading of the manuscript.

This work was supported by U. S. Public Health Service grant AM-17433-10. Dr. M. Field received an award from the Postgraduate Medical Foundation, University of Sydney, Australia, and the Winthrop Travelling Fellowship from the Royal Australasian College of Physicians.

\section{References}

1. Hierholzer, K., and S. Lange. 1975. The effects of adrenal steroids on renal function. In MTP International Review Science: 
Kidney and Urinary Tract Physiology. K. Thurau, editor. Butterworth \& Co., London. 273-334.

2. Möhring, J., and B. Möhring. 1972. Reevaluation of DOCA escape phenomenon. Am. J. Physiol. 223:1237-1245.

3. Young, D. B., and T. E. Jackson. 1982. Effects of aldosterone on potassium distribution. Am. J. Physiol. 243(Regulatory Integrative Comp. Physiol. 12):R526-R530.

4. George, J. M., L. Wright, N. H. Bell, and F. C. Bartter. 1970. The syndrome of primary aldosteronism. Am. J. Med. 48:343-356.

5. Ross, E. J. 1975. Aldosterone and Aldosteronism. Lloyd-Luke, London.

6. Rabinowitz, L. 1979/80. Aldosterone and renal potassium excretion. Renal Physiol. 2:229-243.

7. Edelman, I. S. 1981. Receptors and effectors in hormone action on the kidney. Am. J. Physiol. 241(Renal Fluid Electrolyte Physiol. 10):F333-F339.

8. Fanestil, D. D., and C. S. Park. 1981. Steroid hormones and the kidney. Ann. Rev. Physiol. 43:637-649.

9. Claire, M., M. E. Oblin, J.-L. Steimer, H. Nakane, J. Misumi, A. Michaud, and P. Corvol. 1981. Effect of adrenalectomy and aldosterone on the modulation of mineralocorticoid receptors in rat kidney. J. Biol. Chem. 256:142-147.

10. Lan, N. C., B. Graham, F. C. Bartter, and J. D. Baxter. 1982 Binding of steroids to mineralocorticoid receptors: implications for in vivo occupancy by glucocorticoids. J. Clin. Endocrinol. Metab. 54:332342.

11. Giebisch, G. 1978. Renal potassium transport. In Membrane Transport in Biology. G. Giebisch, D. C. Tosteson, and H. H. Ussing, editors. Springer-Verlag, New York. IVA:215-298.

12. Cortney, M. A. 1969. Renal tubular transfer of water and electrolytes in adrenalectomized rats. Am. J. Physiol. 216:589-598.

13. Hierholzer, K., M. Wiederholt, H. Holzgreve, G. Giebisch, R. M. Klose, and E. E. Windhager. 1965. Micropuncture study of renal transtubular concentration gradients of sodium and potassium in adrenalectomized rats. Pflügers Arch. 285:193-210.

14. Wiederholt, M., and B. Wiederholt. 1968. Der Einfluss von Dexamethason auf die Wasser- und Elektrolytausscheidung adrenalektomierter Ratten. Pflügers Arch. 302:57-78.

15. Stanton, B. A., and G. H. Giebisch. 1982. Potassium transport by the renal distal tubule: effects of potassium loading. Am. J. Physiol. 243(Renal Fluid Electrolyte Physiol. 12):F487-F493.

16. Bia, M. J., K. Tyler, and R. A. DeFronzo. 1982. The effect of dexamethasone on renal electrolyte excretion in the adrenalectomized rat. Endocrinology. 111:882-888.

17. Bia, M. J., K. Tyler, and R. DeFronzo. 1983. The effect of dexamethasone on renal potassium excretion and acute potassium tolerance. Endocrinology. 113:1690-1696.

18. Campen, T. J., D. A. Vaughn, and D. D. Fanestil. 1983. Mineralo- and glucocorticoid effects on renal excretion of electrolytes. Pflügers Arch. 399:93-101.

19. Garrod, O., S. A. Davies, and G. Cahill. 1955. The action of cortisone and desoxycorticosterone acetate on glomerular filtration rate and sodium and water in the adrenalectomized dog. J. Clin. Invest. 34:761-776.

20. Hiatt, N., L. W. Chapman, M. B. Davidson, and J. A. Sheinkopf. 1979. Adrenal hormones and the regulation of serum potassium in potassium-loaded adrenalectomized dog. Endocrinology. 105:215-219.

21. Wilcox, C. S., D. A. Cemerikic, and G. Giebisch. 1982.
Differential effects of acute mineralo- and glucocorticosteroid administration on renal acid elimination. Kidney Int. 21:546-556.

22. Martin, R. S., W. J. Jones, and J. P. Hayslett. 1983. Animal model to study the effect of adrenal hormones on epithelial function. Kidney Int. 24:386-391.

23. Field, M. J., B. A. Stanton, and G. H. Giebisch. 1984. Influence of $\mathrm{ADH}$ on renal potassium handling: a micropuncture and microperfusion study. Kidney Int. 25:502-511.

24. Good, D. W., and F. S. Wright. 1979. Luminal influences on potassium secretion: sodium concentration and fluid flow rate. Am. $J$ Physiol. 236(Renal Fluid Electrolyte Physiol. 5):F192-F205.

25. Stanton, B. A., D. Biemesderfer, J. B. Wade, and G. Giebisch. 1981. Structural and functional study of the rat distal nephron: effects of potassium adaptation and depletion. Kidney Int. 19:36-48.

26. Snedecor, G. W., and W. G. Cochran. 1980. Statistical Methods. Iowa State Univ. Press, Ames, IA. Seventh ed.

27. Good, D. W., H. Velazquez, and F. S. Wright. 1984. Luminal influences on potassium secretion: low sodium concentration. Am. J. Physiol. 246(Renal Fluid Electrolyte Physiol. 15):F609-F619.

28. Stokes, J. B. 1981. Potassium secretion by cortical collecting tubule: relation to sodium absorption, luminal sodium concentration, and transepithelial voltage. Am. J. Physiol. 241(Renal Fluid Electrolyte Physiol. 10):F395-F402.

29. Fimognari, G. M., D. D. Fanestil, and I. S. Edelman. 1967. Induction of RNA and protein synthesis in the action of aldosterone in the rat. Am. J. Physiol. 213:954-962.

30. Wiederholt, M., C. Behn, W. Schoormans, and L. Hansen. 1972. Effect of aldosterone on sodium and potassium transport in the kidney. J. Steroid Biochem. 3:151-159.

31. El Mernissi, G., and A. Doucet. 1983. Short-term effects of aldosterone on renal sodium transport and tubular Na-K-ATPase in the rat. Pflügers Arch. 399:139-146.

32. Wiederholt, M., W. Schoormans, F. Fischer, and C. Behn. 1973. Mechanism of action of aldosterone on potassium transfer in the rat kidney. Pflügers Arch. 345:159-178.

33. Peterson, L. N., and F. S. Wright. 1977. Effect of sodium intake on renal potassium excretion. Am. J. Physiol. 233(Renal Fluid Electrolyte Physiol. 2):F225-F234.

34. Schwartz, G. J., and M. B. Burg. 1978. Mineralocorticoid effects on cation transport by cortical collecting tubules in vitro. Am J. Physiol. 235:F576-F585.

35. Horisberger, J.-D., and J. Diezi. 1983. Effects of mineralocorticoids on $\mathrm{Na}^{+}$and $\mathrm{K}^{+}$excretion in the adrenalectomized rat. Am. J. Physiol. 245(Renal Fluid Electrolyte Physiol. 14):F89-99.

36. Howell, D. S., and J. O. Davis. 1954. Relationship of sodium retention to potassium excretion by the kidney during administration of desoxycorticosterone acetate to dogs. Am. J. Physiol. 179:359-363.

37. Khuri, R. N., M. Wiederholt, N. Strieder, and G. Giebisch. 1975. Effects of flow rate and potassium intake on distal tubular potassium transfer. Am. J. Physiol. 228:1249-1261.

38. Wright, F. S., F. G. Knox, S. S. Howards, and R. W. Berliner. 1969. Reduced sodium reabsorption by the proximal tubule of DOCAescaped dogs. Am. J. Physiol. 216:869-875.

39. Farman, N., and J. P. Bonvalet. 1983. Aldosterone binding in isolated tubules. III. Autoradiography along the rat nephron. Am. J. Physiol. 245(Renal Fluid Electrolyte Physiol. 14):F606-F614.

40. Woodhall, P. B., and C. C. Tisher. 1973. Response of the distal tubule and cortical collecting duct to vasopressin in the rat. J. Clin. Invest. 52:3095-3108. 
41. Stanton, B., A. Janzen, T. Klein-Robbenhaar, J. Wade, G. Giebisch, and R. DeFronzo. 1983. Role of physiological levels of aldosterone in regulation of distal tubule morphology and potassium transport. Kidney Int. 23:267. (Abstr.)

42. Allen, G. G., and L. J. Barratt. 1981. Effect of aldosterone on the transepithelial potential difference of the rat distal tubule. Kidney Int. 19:678-686.

43. Petty, K. J., J. P. Kokko, and D. Marver. 1981. Secondary effect of aldosterone on NaK-ATPase activity in the rabbit cortical collecting tubule. J. Clin. Invest. 68:1514-1521.

44. Garg, L. C., M. A. Knepper, and M. B. Burg. 1981. Mineralocorticoid effects on NaK-ATPase in individual nephron segments. Am. J. Physiol. 240(Renal Fluid Electrolyte Physiol. 9):F536-F544.
45. Bia, M. J., K. A. Tyler, and R. A. DeFronzo. 1982. Regulation of extrarenal potassium homeostasis by adrenal hormones in rats. Am. J. Physiol. 242(Renal Fluid Electrolyte Physiol. 11):F641-F644.

46. Schrier, R. W., and S. L. Linas. 1980 . Mechanisms of the defect in water excretion in adrenal insufficiency. Min. Electrolyte Metab. 4:1-7.

47. Stanton, B., A. Janzen, T. Klein-Robbenhaar, J. Wade, G. Giebisch, and R. DeFronzo. 1983. Role of aldosterone (aldo) and dexamethasone (dex) in regulation of renal distal tubule morphology and potassium (K) excretion. Fed. Proc. 42:476. (Abstr.)

48. Mujais, S. K., M. A. Chekal, W. J. Jones, J. P. Hayslett, and A. I. Katz. 1984. Regulation of renal Na-K-ATPase in the rat. Role of the natural mineralo- and glucocorticoid hormones. J. Clin. Invest. 73:13-19. 